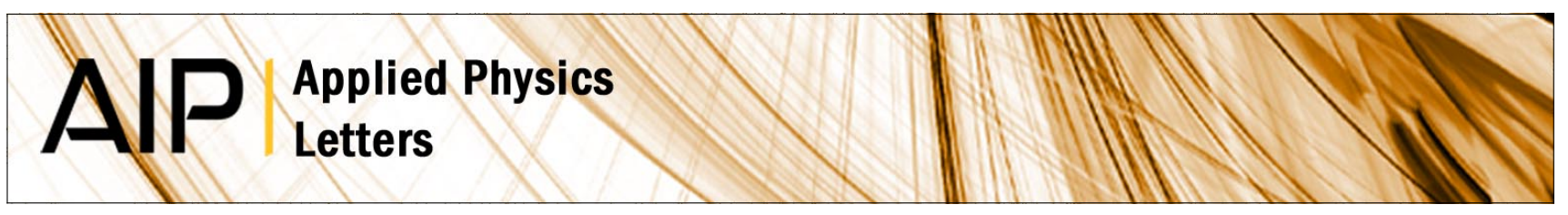

\title{
Germanium fin light-emitting diode
}

S. Saito, K. Oda, T. Takahama, K. Tani, and T. Mine

Citation: Appl. Phys. Lett. 99, 241105 (2011); doi: 10.1063/1.3670053

View online: http://dx.doi.org/10.1063/1.3670053

View Table of Contents: http://apl.aip.org/resource/1/APPLAB/v99/i24

Published by the American Institute of Physics.

\section{Related Articles}

Robust thermal performance of Sr2Si5N8:Eu2+: An efficient red emitting phosphor for light emitting diode based white lighting

Appl. Phys. Lett. 99, 241106 (2011)

Transient capacitance of light-emitting electrochemical cells

APL: Org. Electron. Photonics 4, 268 (2011)

Transient capacitance of light-emitting electrochemical cells

Appl. Phys. Lett. 99, 233306 (2011)

Droop improvement in blue InGaN/GaN multiple quantum well light-emitting diodes with indium graded last barrier

Appl. Phys. Lett. 99, 233501 (2011)

Voltage modulated electro-luminescence spectroscopy to understand negative capacitance and the role of subbandgap states in light emitting devices

J. Appl. Phys. 110, 114509 (2011)

\section{Additional information on Appl. Phys. Lett.}

Journal Homepage: http://apl.aip.org/

Journal Information: http://apl.aip.org/about/about_the_journal

Top downloads: http://apl.aip.org/features/most_downloaded

Information for Authors: http://apl.aip.org/authors

\section{ADVERTISEMENT}

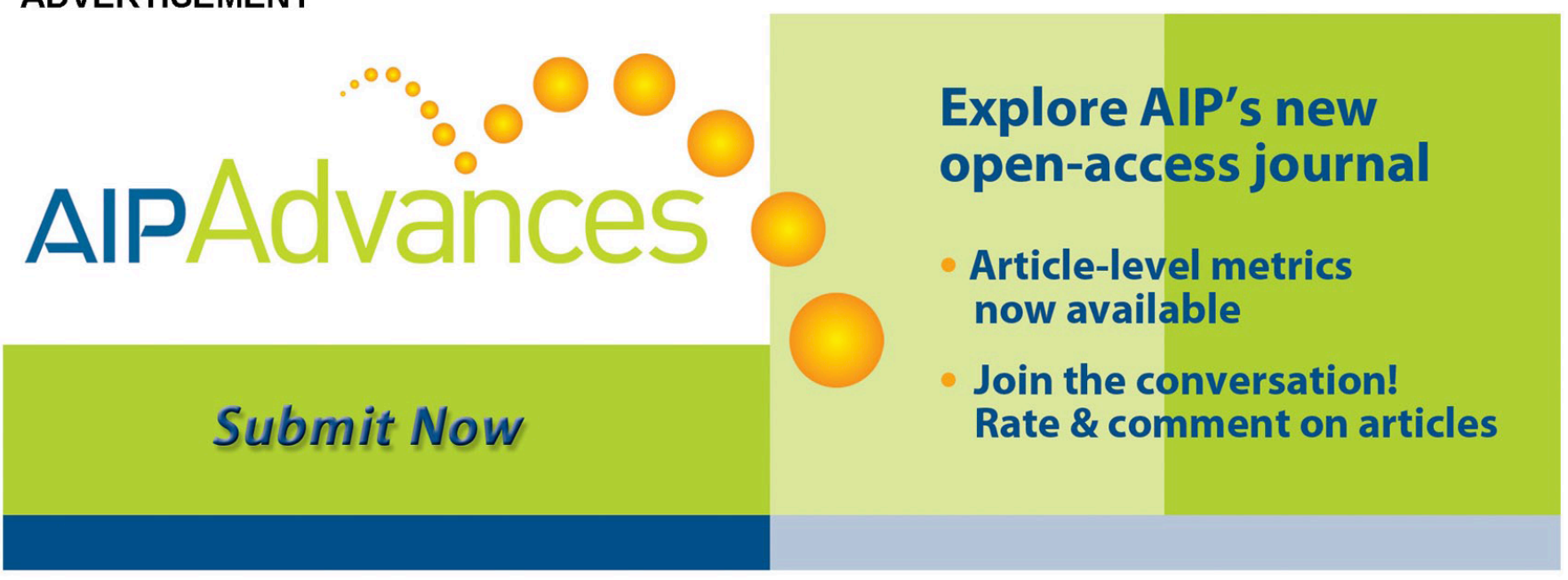




\title{
Germanium fin light-emitting diode
}

\author{
S. Saito, ${ }^{1,2,3, a)}$ K. Oda, ${ }^{1,2,3}$ T. Takahama, ${ }^{3}$ K. Tani, ${ }^{1,2,3}$ and T. Mine ${ }^{3}$ \\ ${ }^{1}$ Photonics Electronics Technology Research Association (PETRA), Kokubunji, Tokyo 185-8601, Japan \\ ${ }^{2}$ Institute for Photonics-Electronics Convergence System Technology (PECST), Kokubunji, \\ Tokyo 185-8601, Japan \\ ${ }^{3}$ Central Research Laboratory, Hitachi, Ltd., Kokubunji, Tokyo 185-8601, Japan
}

(Received 12 October 2011; accepted 28 November 2011; published online 13 December 2011)

\begin{abstract}
We propose a germanium fin light-emitting diode for a monolithic light source on a Si photonics chip. The germanium fins were fabricated by the oxidation condensation of silicon-germanium sidewalls epitaxially grown on silicon fins. We found that a tensile stress is applied to the pure germanium fins by the difference of the thermal expansion coefficient with that of the surrounding oxide. The electroluminescence spectra were consistent with those expected from direct recombination in germanium with a tensile stress. The strong immunity of germanium fins against high current densities would be favourable to achieve population inversions by electrical pumping. (C) 2011 American Institute of Physics. [doi:10.1063/1.3670053]
\end{abstract}

Silicon ( $\mathrm{Si}$ ) photonics is making destructive innovation for optical interconnections in terms of low cost, high volume, and integration of electronics and phtonics devices on a tiny Si chip. ${ }^{1,2}$ But, the only missing component to realize full monolithic integration in a conventional complementarymetal-oxide-semiconductor (CMOS) fabrication line is an electrically pumped laser diode (LD) composed of group IV materials, regardless of substantial progresses in light emissions from Si nano-structures. ${ }^{3-7}$ Germanium $(\mathrm{Ge})$ is a possible alternative candidate to $\mathrm{Si}^{8-14}$ since the conduction band energy of $\mathrm{Ge}$ at the $\Gamma$ point is much lower than that of $\mathrm{Si}$, and therefore, the properties of $\mathrm{Ge}$ are rather close to those of III-V compounds with the direct band gap. ${ }^{10,11}$ In fact, the optical pumped laser ${ }^{10}$ of Ge epitaxially grown on $\mathrm{Si}$ was achieved by the band engineering with a tensile strain and a donor doping at the L valleys. ${ }^{10-13}$ However, the lasing of an electrical pumped Ge-on-Si diode has never been demonstrated. The exact nature of the mechanism why electrical pumping is more difficult has not been completely clarified yet, but several promising attempts such as the higher donor doping $^{10,12}$ and the higher tensile stress ${ }^{13,14}$ were reported. In addition to these approaches, we think that it is important to improve the crystalline quality of $\mathrm{Ge}$, since the huge lattice mismatch of $4.1 \%$ between Ge and Si generates significant amounts of defects, which would act as non-radiative recombination centers, and the state-of-the-art Ge-on-Si diode would be broken without being in population inversion conditions at high injection currents.

The purpose of this paper is to propose a device, called a Ge fin light-emitting diode (FinLED) (Figs. 1(a)-1(c)), and to examine its structural advantage for overcoming the fundamental difficulty of the lattice mismatch. The proposed $\mathrm{Ge}$ fins are embedded in amorphous $\mathrm{SiO}_{2}$, and there is no source of compressive lattice stress subject to Ge fins, in contrast to Ge films directly grown on Si. Therefore, we expect excellent crystalline qualities of the Ge fins, which should be confirmed by electrical measurements in ultralow dark currents under the application of the reverse bias to the diode.

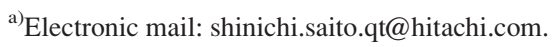

A similar device, called Si fin field-effect transistor (FinFET), was proposed as a double gate transistor at the end of the CMOS scaling, ${ }^{15}$ and a Si chip with billions of integrated Si FinFETs will be launched in the $22 \mathrm{~nm}$ technology. The three-dimensional $(3 D)$ structures of $\mathrm{Si}$ fins are also suitable to realize the multiple quantum wells (MQWs) in Si FinLEDs. ${ }^{7}$ The SiGe FinFETs (Ref. 16) were also fabricated to enhance the hole mobility by the oxidation condensation techniques. ${ }^{16,17}$ The present pure Ge fins can be made by the extensions of previous works, ${ }^{7,15,16}$ and Ge FinLEDs will be integrated with Si or Ge FinFETs on the same chip by small modifications of the process steps.

The essential process flow to fabricate the Ge fin is shown in Figs. 1(d1)-1(d4). We used a Si-on-insulator (SOI) substrate, whose top SOI layer has (001) surface and the horizontal (longitudinal) direction is along the $\langle 100\rangle(\langle 010\rangle)$ direction. The $\mathrm{Si}$ fins were defined by conventional
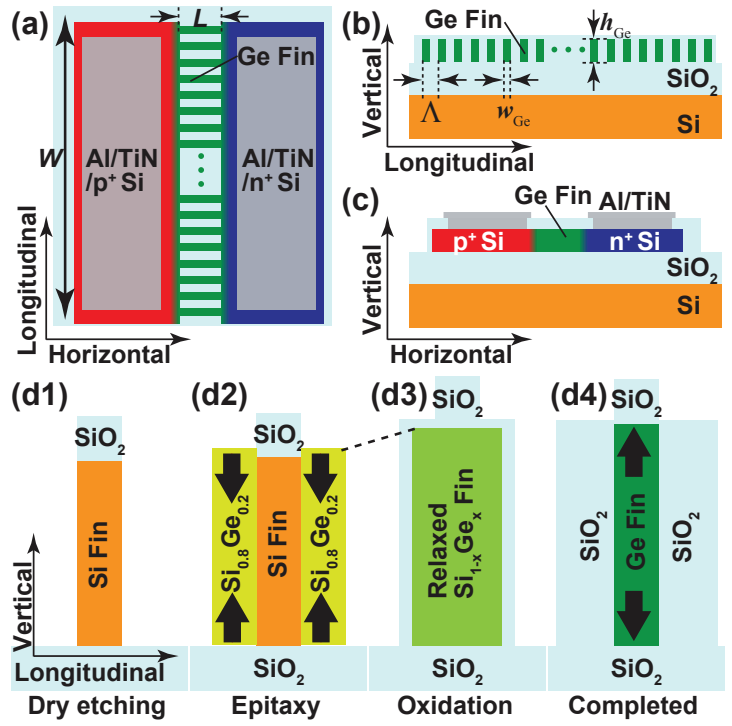

FIG. 1. (Color online) Ge FinLED. Schematic views of device structures from (a) vertical $\langle 001\rangle$, (b) horizontal $\langle 100\rangle$, and (c) longitudinal $\langle 010\rangle$ directions. Active channel width $W$ (length $L$ ) is 100 (1) $\mu \mathrm{m}$. (d1)-(d4) Fabrication flow of Ge fins. 

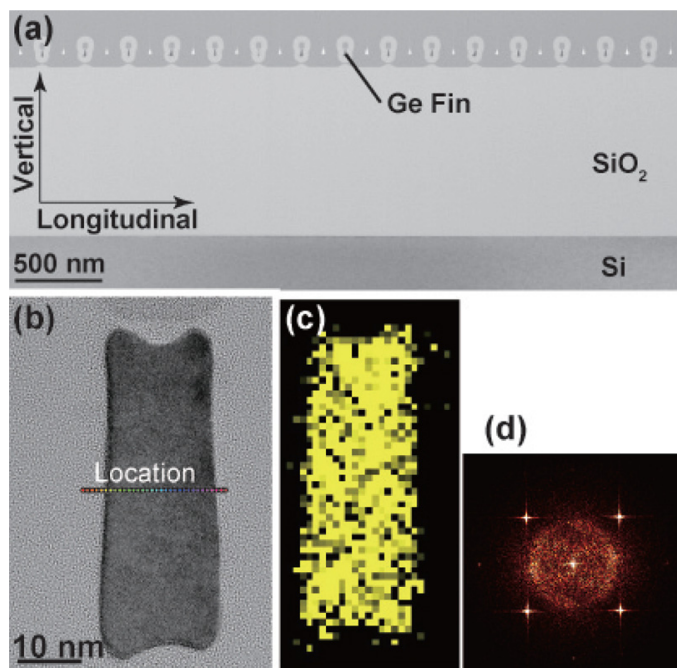

FIG. 2. (Color online) Pure Ge Fin. (a) TEM images after processing, and its (b) enlarged image. (c) Ge mapping images taken by EDX spectroscopy. (d) Diffraction images of Ge fins, showing Ge (100) with tensile strain of $0.26 \%$.

lithography and dry etching processes with $\mathrm{SiO}_{2}$ hard masks (Fig. 1(d1)). After the formation of multi-fins, the heavily doped electrodes are formed by ion implantations and the activation. ${ }^{7}$ The non-doped $\mathrm{Si}_{0.8} \mathrm{Ge}_{0.2}$ was epitaxially grown on the sidewall of the Si fin (Fig. 1(d2)). We expect no substantial increase in crystalline defects as far as the thickness of the grown $\mathrm{Si}_{1-x} \mathrm{Ge}_{x}$ is below the critical thickness. ${ }^{2}$ Next, the $\mathrm{Si}$ atoms inside the fin are selectively oxidized at $900^{\circ} \mathrm{C}$ by the oxidation condensation ${ }^{16,17}$ (Fig. 1(d3)). During the oxidation, the $\mathrm{Si}$ atoms in the $\mathrm{Si}_{1-x} \mathrm{Ge}_{x}$ fin were replaced with the Ge atoms, and the compressive stress was accumulated in the $\mathrm{Si}_{1-x} \mathrm{Ge}_{x}$ fin ${ }^{16}$ as far as $\mathrm{Si}$ atoms in the fin were remained. After the complete oxidation of the $\mathrm{Si}$ atoms, however, the pure Ge fin can fully relax at high temperatures with a help of its $3 D$ structure stretching towards open boundaries, since all single crystalline $\mathrm{Si}$ atoms inside the fins were consumed to form the amorphous $\mathrm{SiO}_{2}$. By reducing temperatures down to the room temperature, the tensile stress ${ }^{18}$ will be applied to Ge fins due to the difference of the thermal expansion coefficients between the Ge fin and the surrounding $\mathrm{SiO}_{2}$ (Fig. 1(d4)). Finally, the $\mathrm{Al} / \mathrm{TiN}$ electrodes were patterned, and the $\mathrm{H}_{2}$ annealing were made to passivate the interface traps.

The fabricated Ge FinLED is shown in Figs. 2(a) and 2(b). The Ge fins with a width $w_{\mathrm{Ge}}$ of $18.7 \pm 1.1 \mathrm{~nm}$ and a height $h_{\mathrm{Ge}}$ of $51.7 \pm 3.0 \mathrm{~nm}$ were fabricated with a pitch $\Lambda$ of $150 \mathrm{~nm}$. According to the atomic mapping taken by the energy dispersive $\mathrm{x}$-ray (EDX) spectroscopy, we confirmed that Ge atoms were condensed inside the fin and no apparent $\mathrm{Si}$ atoms were found in the fin (Fig. 2(c)). This confirms the replacement of $\mathrm{Si}$ atoms with $\mathrm{Ge}$ atoms. Furthermore, the diffraction patterns (Fig. 2(d)) obtained by the Fourier transformation of the image of Fig. 2(b) are consistent with those from Ge (100) surface with a tensile strain of $0.41 \% \pm 0.19 \%$ along the longitudinal direction and a tensile strain of $0.50 \% \pm 0.19 \%$ along the vertical direction. The slight difference of the strain would come from the open boundaries of the fins along the vertical direction (Fig. 1(d4)). The larger tensile strain of Ge fins than that of $\mathrm{Ge}$ grown on $\mathrm{Si}^{18}{ }^{18} 0.20 \%$, was expected from
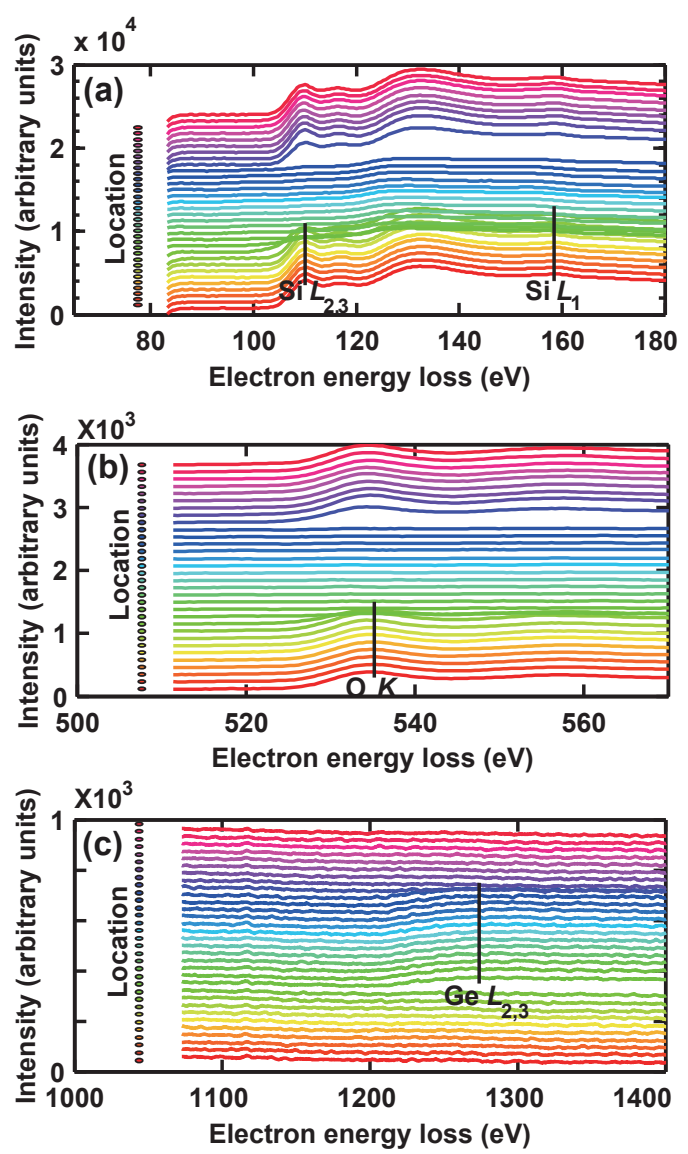

FIG. 3. (Color online) Si FinLED. (a) Schematic device structures. Active channel width (length) is 500 (1) $\mu \mathrm{m}$, and cavity length (width) is $500(0.6)$ $\mu \mathrm{m}$. (b) TEM images after processing. Inset shows single $\mathrm{Si}$ (100) fin.

the larger difference of the expansion coefficients between $\mathrm{Ge}$ and $\mathrm{SiO}_{2}$ than that between $\mathrm{Ge}$ and $\mathrm{Si}$.

The atomic profile of the Ge fin was also examined by the electron energy-loss spectroscopy (EELS) ${ }^{19}$ at the location shown in the transmission electron microscope (TEM) image of Fig. 2(b). We can clearly identify that no signal of Si $\mathrm{L}_{2,3}\left(2 \mathrm{p}^{1 / 2}, 2 \mathrm{p}^{3 / 2}\right)$ or $\mathrm{Si}_{1}\left(2 \mathrm{~s}^{1 / 2}\right)$ edge from the fin was found (Fig. 3(a)), and the oxygen (O) $\mathrm{K}\left(1 \mathrm{~s}^{1 / 2}\right)$ edge signals were found outside the fin (Fig. 3(b)). Inside the fin, $\mathrm{Ge}_{2,3}$ edge signals were detected (Fig. 3(c)). These results confirm that $\mathrm{Si}$ atoms inside the fin were consumed during the oxidation to form the pure $\mathrm{Ge}$ fin surrounded by $\mathrm{SiO}_{2}$. We observed sharp spectral change at the $\mathrm{Ge}$ fin $/ \mathrm{SiO}_{2}$ interface,

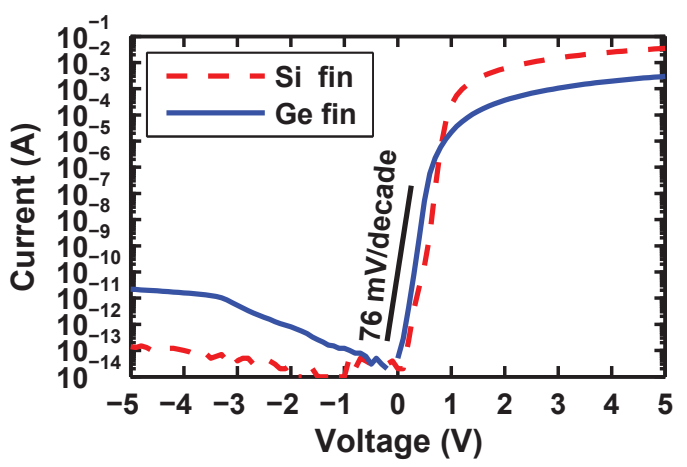

FIG. 4. (Color online) Transport characteristics of Ge FinLED, compared with Si FinLED. 

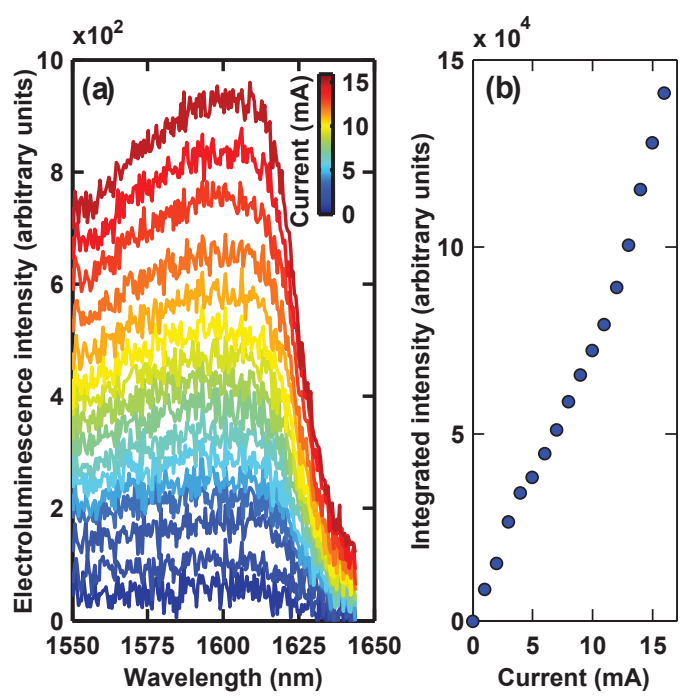

FIG. 5. (Color online) Optical characteristics of Ge FinLED. (a) Electroluminescence spectra. (b) Integrated intensities.

and no intermediate suboxide transition layer was found in the present spatial resolution of $1.3 \mathrm{~nm}$.

Next, we show the electrical and optical characteristics of the Ge FinLED. All measurements were made at room temperatures. In Fig. 4, we show the current-voltage characteristics of the Ge FinLED with a reference result of the $\mathrm{Si}$ FinLED. ${ }^{7}$ We found excellent rectifying characteristics with the ideality factor of 1.27 in both Ge and Si FinLEDs, showing good interfacial qualities with low interface traps. The dark currents of the Ge FinLED are increased substantially compared with those of the Si FinLED, but the observed ultralow dark current density of $1.86 \times 10^{-5}\left(3.41 \times 10^{-3}\right) \mathrm{A} / \mathrm{cm}^{2}$ at the reverse bias of $1(5) \mathrm{V}$ is comparable to those reported as the record low dark currents. ${ }^{20}$ The forward currents of the Ge Fin LED are reduced compared with those of the $\mathrm{Si}$ FinLED, presumably because of the type II band alignment ${ }^{8}$ at the $\mathrm{Ge}$ fin/Si electrode interface. Nevertheless, the forward current density of the Ge Fin LED can be extremely high, exceeding the values of $3.40 \times 10^{3}\left(4.62 \times 10^{5}\right) \mathrm{A} / \mathrm{cm}^{2}$ at the bias of $1(5) \mathrm{V}$ without a breakdown. As a result, high on/off ratio of $1.83 \times 10^{8}\left(1.35 \times 10^{8}\right)$ at the bias of $\pm 1( \pm 5) \mathrm{V}$ was achieved. These excellent diode characteristics suggest good crystalline qualities of the Ge fins.

Finally, electroluminescence (EL) spectra by constant current injections are shown in Fig. 5. We observed broad spectrum centred around $1600 \mathrm{~nm}$ (Fig. 5(a)), as expected from the direct recombination at the $\Gamma$ point $^{10}$ in Ge fins. The EL spectra of the Ge FinLED were red-shifted from the photoluminescence (PL) spectra of the bulk Ge centred at $1540 \mathrm{~nm}$. These results are also consistent with the fact that the tensile strain is applied to the Ge fins by the difference of the thermal expansion coefficients. ${ }^{18}$ As shown in Fig. 5(b), the integrated optical intensities were increased by increas- ing currents, but there was no substantial change indicating stimulated emissions. The aggressive n-type doping ${ }^{10}$ and/or the strong tensile stress ${ }^{13}$ of $\mathrm{Si}_{3} \mathrm{~N}_{4}$ as well as proper waveguide designs are thus inevitable to achieve the lasing of $\mathrm{Ge}$ fins by current injections.

In conclusion, we have proposed Ge fin light-emitting diodes for monolithic light sources in future Si photonics chips. We fabricated and characterized pure Ge fins and confirmed replacements of Si atoms with Ge atoms occurred by oxidation condensation. We observed excellent electrical characteristics of Ge fin diodes with high on/off ratio of the order $10^{8}$. The electroluminescence spectra were consistent with those expected from direct recombination in Ge with a tensile stress. The strong breakdown characteristics of the present device against high current densities of the order 1 $\mathrm{MA} / \mathrm{cm}^{2}$ is an advantage to increase the injected carrier densities for achieving the population inversion and increasing the net gain. Therefore, the Ge fin is one of the most promising candidates to overcome fundamental difficulties to make excellent Ge structures on a Si-on-insulator substrate.

We thank Professor Y. Arakawa, Professor S. Iwamoto, and Dr. S. Kako for enlightening discussions. This research is granted by JSPS through FIRST Program initiated by CSTP.

${ }^{1}$ R. A. Soref and J. P. Lorenzo, IEEE Electron Device Lett. 21, 953 (1985).

${ }^{2}$ R. People, IEEE J. Quantum Electron. 22, 1696 (1986).

${ }^{3}$ L. T. Canham, Appl. Phys. Lett. 57, 1046 (1990).

${ }^{4}$ N. Koshida and H. Koyama, Appl. Phys. Lett. 60, 347 (1991).

${ }^{5}$ L. Pavesi, L. D. Negro, C. Mazzoleni, G. Franzò, and F. Priolo, Nature 408, 440 (2000).

${ }^{6}$ Y. Suwa and S. Saito, Phys. Rev. B 79, 233308 (2009).

${ }^{7}$ S. Saito, T. Takahama, K. Tani, M. Takahashi, T. Mine, Y. Suwa, and D. Hisamoto, Appl. Phys. Lett. 98, 261104 (2011).

${ }^{8}$ S. Fukatsu, H. Sunamura, Y. Shiraki, and S. Komiyama, Appl. Phys. Lett. 71, 258 (1997).

${ }^{9}$ J. Menéndez and J. Kouvetakis, Appl. Phys. Lett. 85, 1175 (2004).

${ }^{10}$ J. Liu, X. Sun, R. Camacho-Aguilera, L. C. Kimerling, and J. Michel, Opt. Lett. 35, 679 (2010).

${ }^{11}$ X. Sun, J. Liu, L. C. Kimerling, and J. Michel, IEEE J. Sel. Top. Quantum Electron. 16, 124 (2010).

${ }^{12}$ G. Shambat, S. L. Cheng, J. Lu, Y. Nishi, and J. Vuckovic, Appl. Phys. Lett. 97, 241102 (2010).

${ }^{13}$ M. de Kersauson, M. E. Kurdi, S. David, X. Checoury, G. Fishman, S. Sauvage, R. Jakomin, G. Beaudoin, I. Sagnes, and P. Boucaud, Opt. Express 19, 17925 (2011).

${ }^{14}$ Y. Huo, H. Lin, R. Chen, M. Makarova, Y. Rong, M. Li, T. I. Kamins, J. Vuckovic, and J. S. Harris, Appl. Phys. Lett. 98, 011111 (2011).

${ }^{15}$ D. Hisamoto, T. Kaga, and E. Takeda, IEEE Trans. Electron Devices 38, 1419 (1991).

${ }^{16}$ T. Tezuka, E. Toyoda, T. Irisawa, N. Hirashita, Y. Moriyama, N. Sugiyama, K. Usuda, and S. Takagi, Appl. Phys. Lett. 94, 081910 (2009).

${ }^{17}$ F. K. LeGoues, R. Rosenberg, T. Nguyen, F. Himpsel, and B. S. Meyerson, J. Appl. Phys. 65, 1724 (1989).

${ }^{18}$ Y. Ishikawa, K. Wada, D. D. Cannon, J. Liu, H. C. Luan, and L. C. Kimerling, Appl. Phys. Lett. 82, 2044 (2003).

${ }^{19}$ D. A. Muller, T. Sorsch, S. Moccio, F. H. Baumann, K. Evans-Lutterodt, and G. Timp, Nature 399, 758 (1999).

${ }^{20}$ J. Osmond, G. Isella, D. Chrastina, R. Kaufmann, M. Acciarri, and H. von Känel, Appl. Phys. Lett. 94, 201106 (2009). 